\title{
New Strategy for the Cleaning of Paper Artworks: A Smart Combination of Gels and Biosensors
}

\author{
Laura Micheli, ${ }^{1,2}$ Claudia Mazzuca, ${ }^{1}$ Eleonora Cervelli, ${ }^{1}$ and Antonio Palleschi ${ }^{1}$ \\ ${ }^{1}$ Department of Chemical Sciences and Technologies, University of Rome "Tor Vergata", Via della Ricerca Scientifica, 00133 Rome, Italy \\ ${ }^{2}$ Consorzio Interuniversitario Biostrutture e Biosistemi "INBB", Viale Medaglie d'Oro 305, 00136 Rome, Italy
}

Correspondence should be addressed to Laura Micheli; laura.micheli@uniroma2.it

Received 3 April 2014; Accepted 4 August 2014; Published 2 September 2014

Academic Editor: Ipsita Banerjee

Copyright (C) 2014 Laura Micheli et al. This is an open access article distributed under the Creative Commons Attribution License, which permits unrestricted use, distribution, and reproduction in any medium, provided the original work is properly cited.

In this work an outlook on the design and application, in the cultural heritage field, of new tools for diagnostic and cleaning use, based on biocompatible hydrogels and electrochemical sensors, is reported. The use of hydrogels is intriguing because it does not require liquid treatment that could induce damage on artworks, while electrochemical biosensors not only are easy to prepare, but also can be selective for a specific compound and therefore are suitable for monitoring the cleaning process. In the field of restoration of paper artworks, more efforts have to be done in order to know how to perform the best way for an effective restoration. Rigid Gellan gel, made up of Gellan gum and calcium acetate, was proposed as a paper cleaning treatment, and selective biosensors for substances to be removed from this gel have been obtained by choosing the appropriate enzymes to be immobilized. Using this approach, it is possible to know when the cleanup process will be completed, avoiding lengthy and sometimes unnecessary cleaning material applications.

\section{Introduction}

Paper is difficult to be restored, due to its fragility, its degradation process, and its multicomponent composition. The main paper component is cellulose, a polysaccharide made up of $\beta$-glucose units linked together by $\beta(1 \rightarrow 4)$ glycosidic bonds [1]. Structural changes due to ageing lead to a decrease in the stability of the material and in its strength and a change in color [2]. Critical steps, during restoring of paper material, are the cleaning of the sheets, the $\mathrm{pH}$ change, the optimization of the degree of humidity, and the glue removal. It is also very important that the time of the cleaning process is optimized in order to remove all pollution and degradation products and to minimize invasive treatment that can lead to irreversible damage.

In the last year, the research in cultural heritage was focalized on the study of noninvasive diagnostic tools for the determination of paper artworks degradation [3]. Different techniques promise to be useful for cultural heritage applications, due to their specific properties. The combination of innovative and noninvasive material, such as an opportune hydrogel with selective electrochemical biosensors, gives the possibility to verify the degradation conditions of the paper artworks and to clean them efficiently, monitoring the removal process of pollution and degradation products. Electrochemical biosensors, based on enzyme, have been widely used in fields such as health care, food safety, and environmental monitoring. Health care is the main area in these applications, to monitor, for example, blood glucose levels and diabetics by glucose biosensors or the reliable detection of urea at home or in the hospital on patients with renal disease. Industrial applications for biosensors include monitoring fermentation broths or food processing procedures through detecting concentrations of glucose and other fermentative end products $[4,5]$. Many of these biosensors, developed in these fields, are also potentially useful for applications in cultural heritage area, for conservation or characterization of several important materials such as paper, paintings, textiles, or glass.

Gellan gel has been in use since 2003 as cleaning agent for paper artworks at the Istituto Centrale per il Restauro e la Conservazione del Patrimonio Archivistico e Librario 
(ICPAL, Rome, Italy) [6]. It is made up of deacylated Gellan gum and calcium acetate. The resulting gel is very transparent, thermoreversible, and rigid; it is able to gradually release the water contained within their polymer network [7] and also to absorb the water-soluble degradation products present on paper. Finally, due to its viscoelastic properties, its application and removal are fairly simple while allowing a localized cleaning operation (Figure 1). Since it is stiff and nonsticky, it can be peeled from a surface in one piece, minimizing residues [8]. These features make this gel particularly suitable to perform safer wet cleaning treatments on paper artworks, ensuring the maintenance of the structural and aesthetic properties of paper.

The aim of this research is to achieve the effectiveness of this innovative experimental approach, through the physicochemical characterization of opportune hydrogel coupled with the monitoring electrochemical system. This system gives the possibility to verify the degradation conditions of the paper artworks and to clean it efficiently, monitoring the removal process of pollution and degradation products. Moreover, some specific examples applied on paper underline the advantage and the potentiality of the combination of these materials with biosensors with respect to the traditional old paper cleaning methodologies.

\section{Gellan Gel}

Innovative methods for the treatment of paper materials have been studied using materials applied in the food and biomedical areas $[10,11]$. One of these is the deacylated Gellan, a high molecular weight polysaccharide, already used as gelling agent in the biomedical, pharmaceutical, and industrial fields. It is a linear anionic heteropolysaccharide produced by Pseudomonas elodea and consists of $(1,3)-\beta$ D-Glucose, $(1,4)-\beta$-D Glucuronic acid, $(1,4)-\beta$-D-Glucose, and $(1,4)-\alpha$-L-Rhamnose repeating units [12]. In the native polymer two acyl substituents, L-glyceryl at $\mathrm{O}(2)$ and acetyl at $\mathrm{O}(6)$, are present at the 3-linked glucose and, on average, there is one glyceryl per repeating unit and one acetyl every two repeating units [13]. This polymer forms hydrogels whose sol-gel transition process is temperature dependent $[14,15]$; in particular, the polysaccharide, in presence of calcium salts, forms hard and rigid gel with a slow syneresis rate; moreover, it is homogeneous, transparent, and stable to $\mathrm{pH}$ variations $[16,17]$. The $\mathrm{pH}$ stability assures that the hydrogel can be safely applied to every paper sample whatever its $\mathrm{pH}$ value is.

The present outlook will discuss and compare the results obtained by applying the Gellan hydrogel cleaning method and the traditional cleaning technique (i.e., immersion in a deionized water bath) on different paper samples.

To assess the effectiveness and safety of the proposed cleaning method on the several samples under examination we have employed a multitechnique approach, using high-performance liquid chromatography (HPLC), Fourier transform infrared spectroscopy (FTIR), scanning electron microscopy (SEM), and $\mathrm{pH}$ measurements. The compatibility and cleaning ability of the Gellan gel have been assured on paper samples belonging to different centuries (from XVI to

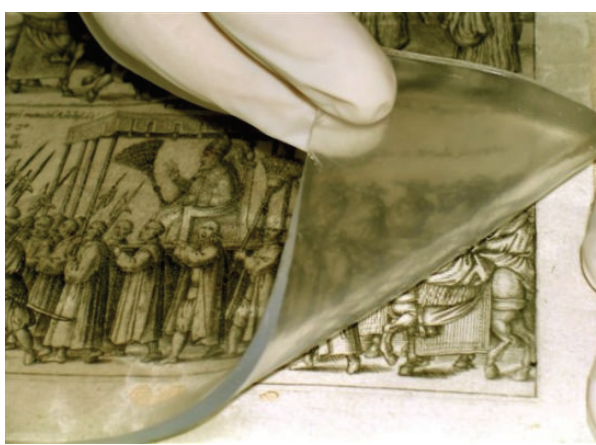

FIGURE 1: Application of Gellan gel on paper artworks.

XIX) and, therefore, characterized by different degradation condition and paper composition as obtained by Graff " $\mathrm{C}$ " staining experiments, HPLC measurements, and FTIR spectra [18-21]. We have assessed that Gellan gel can clean paper samples independently from their characteristics and age.

More in detail, paper samples were divided in two groups and treated, respectively, by immersion in deionized water (Figure 2(a)) and by contact with Gellan gel (Figure 2(b)). In both cases, the cleaning procedures were carried out for $60 \mathrm{~min}$ at room temperature. After the cleaning step, the paper samples were left to dry at room temperature. SEM images (Figure 3) showed that both samples, after immersion in water and hydrogel treatment, seemed cleaner and no swelling or fraying was present; moreover, no gel residues were visible in the images on samples analyzed after gel treatment. FTIR analysis on samples analyzed before and after treatment was indeed comparable, suggesting that no residues of gel were present (Gellan gel has characteristic IR peaks at 1602,1408 , and $1010 \mathrm{~cm}^{-1}$, clearly distinguishable from those of paper samples); no detectable chemical degradation of cellulose took place as a result of the hydrogel treatment. The presence of hydrogel residues on paper samples were investigated also by performing HPLC analysis of aqueous extracts of Gellan gel before and after treatment on Whatman paper samples (data not shown). At the same time, the increase of $\mathrm{pH}$ values (Table 1), obtained after both cleaning procedures, indicated that acidic components involved in degradation processes were removed; anyhow, it should be noted that the decrease in acidity is slightly higher after Gellan gel cleaning procedure; this phenomenon can be explained by taking into account both the diffusive properties of molecules in the hydrogel and the intrinsic nature of it, rich in alcohol groups, capable to interact with the acidic residues on paper.

Furthermore, Gellan gel is able to remove pollution and degradation products from paper as much as the immersion in water, as shown by the comparison between the chromatograms of samples from XVIII century treated with the two methods (Figure 4). Peaks, in both cases, had almost disappeared. These results indicate that hydrogel treatment is an efficient cleaning method and does not cause change in the morphology of paper.

After investigating the cleaning ability of the Gellan gel "per se" (see the region between 3 and 10 minutes, where 


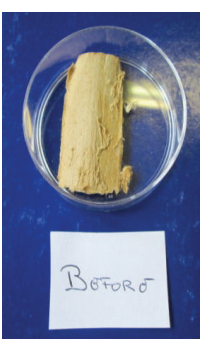

(A)

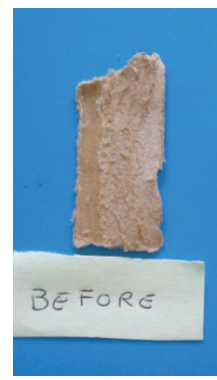

(A)

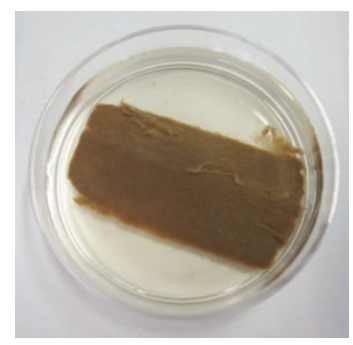

(B)

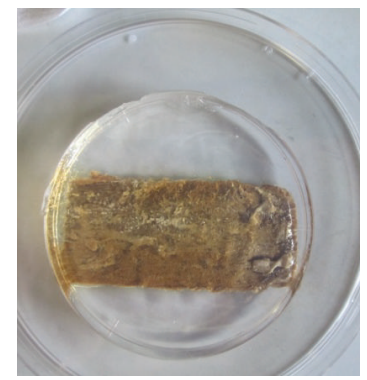

(B)

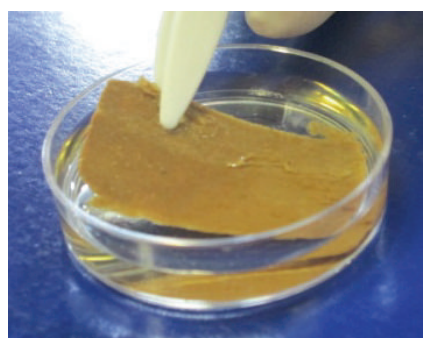

(C)

(a)

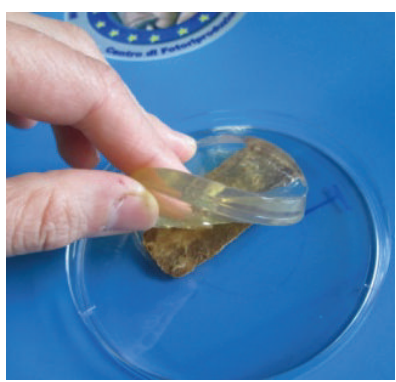

(C)

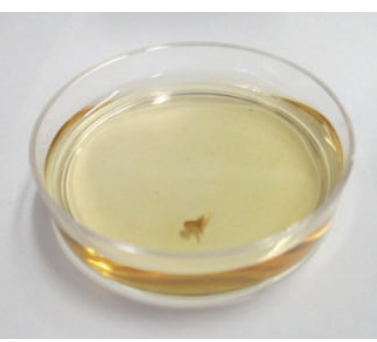

(D)

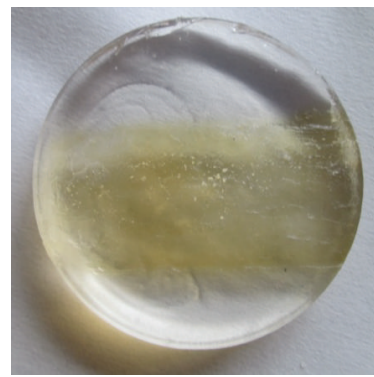

(D)

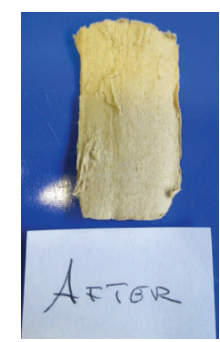

(E)

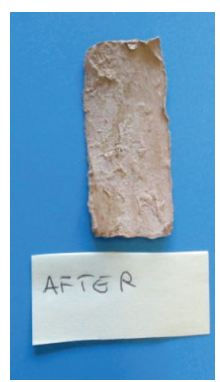

(E)

(b)

Figure 2: (a) Cleaning procedure with water immersion: (A) paper fragment immersed in water bath; (B) paper fragment in water; (C) removal of paper fragment from water bath after $1 \mathrm{~h}$; (D) the dirt removed from paper by deionized water; (E) paper sample after water immersion. (b) Cleaning procedure using Gellan gel: (A) paper fragment before treatment with gel; (B) application of gel on paper fragment; (C) removal of gel from paper fragment in one step after $1 \mathrm{~h}$; (D) the dirt removed from the paper by the yellowish color of the gel is easy to see; (E) paper sample after gel treatment.

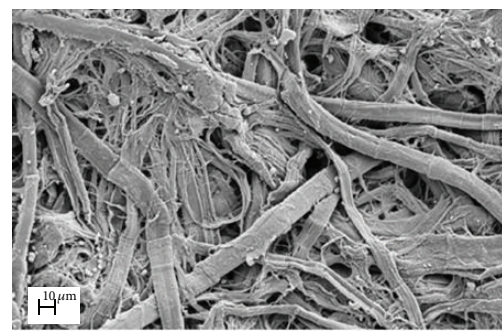

(a)

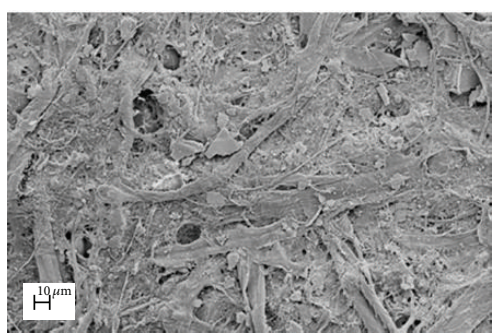

(d)

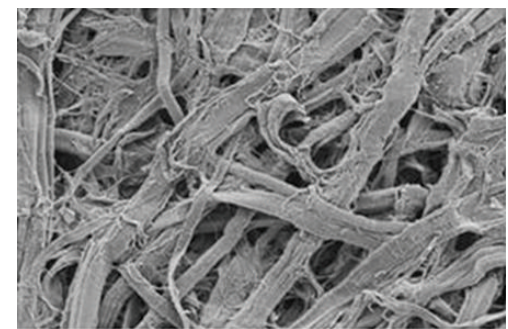

(b)

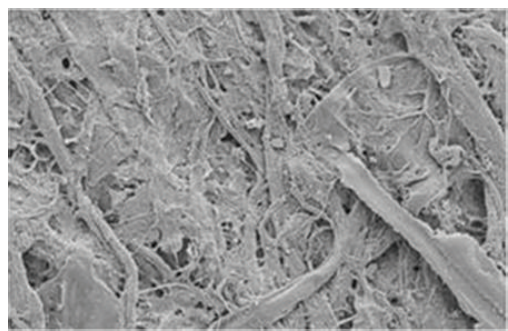

(e)

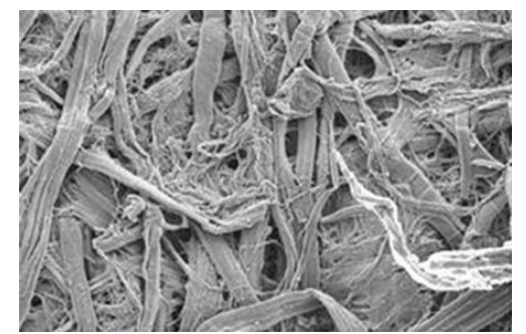

(c)

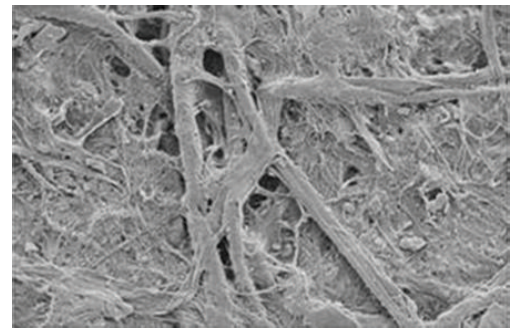

(f)

FIGURE 3: SEM images of paper samples belonging to XVII (upper panel) and XIX (lower panel) century, respectively, before cleaning (left), after Gellan gel treatment (middle), and after immersion in water (right) [9]. 


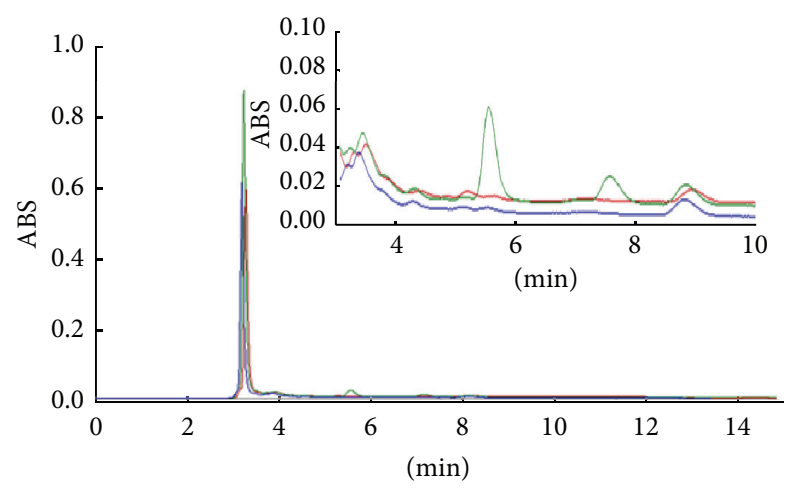

FIGURE 4: Comparison of HPLC chromatograms of XVIIII century before (green line) and after cleaning treatment with gellanGellan gel (blue) and water bath (red). Insert: detail of chromatogram, region between 3 and 10 minutes.

TABLE 1: $\mathrm{pH}$ values before and after cleaning treatments [9].

\begin{tabular}{lccc}
\hline & Before & $\begin{array}{c}\text { After } \\
\text { (cleaning step with } \\
\text { gel) }\end{array}$ & $\begin{array}{c}\text { After } \\
\text { (traditional clearing } \\
\text { step) }\end{array}$ \\
\hline XVI & $8.5 \pm 0.1$ & $9.4 \pm 0.2$ & $9.3 \pm 0.1$ \\
XVII & $7.1 \pm 0.2$ & $7.6 \pm 0.1$ & $7.9 \pm 0.2$ \\
XVIII & $8.6 \pm 0.2$ & $9.0 \pm 0.2$ & $8.9 \pm 0.2$ \\
XIX & $5.1 \pm 0.1$ & $6.4 \pm 0.1$ & $5.9 \pm 0.1$ \\
\hline
\end{tabular}

the peaks of the components present on the untreated paper disappear after treatment with the gel), we also evaluated the possibility of using Gellan gel as a carrier of tuned cleaning agent. Gellan gel could be a not suitable agent to remove hydrophobic contaminants, due to its hydrophilic nature; to this end, we performed preliminary experiments by preparing a "mixed Gellan gel" (called Gellan/PLU gel); PLU gel is Gellan gel mixed with a physical hydrogel made up of $\alpha$-cyclodextrin $(\alpha-\mathrm{CD})$ and of a pluronic copolymer (poly(ethylene oxide) ${ }_{20}$-poly(propylene oxide $)_{70}$ poly(ethylene oxide $\left.)_{20}\right)\left(\mathrm{PEO}_{20}-\mathrm{PPO}_{70}-\mathrm{PEO}_{20}\right)$ (PLU gel) [22-24]. PLU gel has amphiphilic properties and its ability to remove hydrophobic contaminants like linseed oil has been already assessed in our laboratory $[25,26]$.

The efficiency of cleaning of the proposed hydrogel was tested first on filter paper samples impregnated with linseed oil, as representative of fresh hydrophobic contamination; linseed oil was chosen because it is a natural substance that can mimic oily contaminants and it is widely used as a carrier for pigments in inks and as a primer for glossy paper [27, 28].

FTIR-ATR measurements (Figure 5) show that the two hydrogels and, particularly, PLU gel have partially removed the oil after 60 minutes treatment. Furthermore, in this respect, the absorbance ratio (called A.R. in the following) between two peak areas, one centered at $1740 \mathrm{~cm}^{-1}$ due to oil [29] and the other at $1000 \mathrm{~cm}^{-1}$ mainly due to cellulose [30], seemed to be particularly diagnostic. This ratio changes went from 0.30 for the untreated sample to 0.23 for paper cleaned with Gellan gel alone and fell to 0.19 in the case of the sample

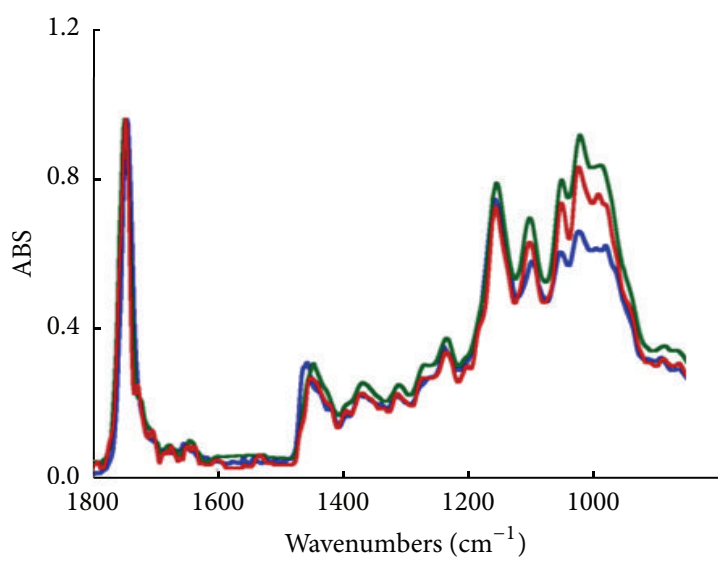

FIGURE 5: FTIR spectra of paper samples soiled with linseed oil, uncleaned (blue line), cleaned with Gellan gel (red line), and cleaned with Gellan/PLU gel (green line). Spectra are normalized to the $1740 \mathrm{~cm}^{-1}$ peak for clarity.

cleaned with the Gellan/PLU gel. These data indicated that Gellan gel alone was a good cleaning agent for hydrophobic contaminants and that the addition of the PLU gel caused an increase of its cleaning ability.

To assess the efficay of the proposed Gellan/PLU gel on real paper samples, fragments from the volume of XVIII century were soiled with linseed oil and aged as representative of old hydrophobic contamination; also in this case, the analysis of FTIR-ATR spectra indicated that A.R. decreased from 0.208 for the untreated sample to 0.102 and 0.098 for paper samples treated with Gellan gel and Gellan/PLU gel, respectively. HPLC experiments (Figure 6) confirmed these results, indicating that the Gellan/PLU gel was slightly more able to remove high molecular weight hydrophobic contaminants.

Another important issue in the paper restoration field is represented by the presence of specific contaminations on the paper sheets, difficult to remove by using the previous reported protocols. The most common example of this class of contamination is represented by the glues, often present in previous restoring actions. The removal of old glue from artworks is very important for their preservation; during ageing, in fact, the structural transformations of the glue produce a loss in compactness, yellowing, and an acidity increase, thus accelerating the mechanical fragility of the artwork itself. The use of hydrolytic enzymes, immobilized in hydrogel as agents for biocompatible cleaning, represents an interesting and advantageous alternative to traditional methods (i.e., use of water or mixed water/ethanol packs), resulting to be very important for a significant reduction in the application time of the cleaning up, due to the specific and targeted enzyme activity. Among other advantages of the hydrogel here presented, Gellan gel is suitable to be used as carrier for enzymes. In this context, some experiments were performed using the hydrogel with alpha amylase enzymes (called Enzymatic Gellan gel) on filter paper covered with starch paste for one hour (in this case, alpha amylase enzyme was used because it can hydrolyze the starch paste). 


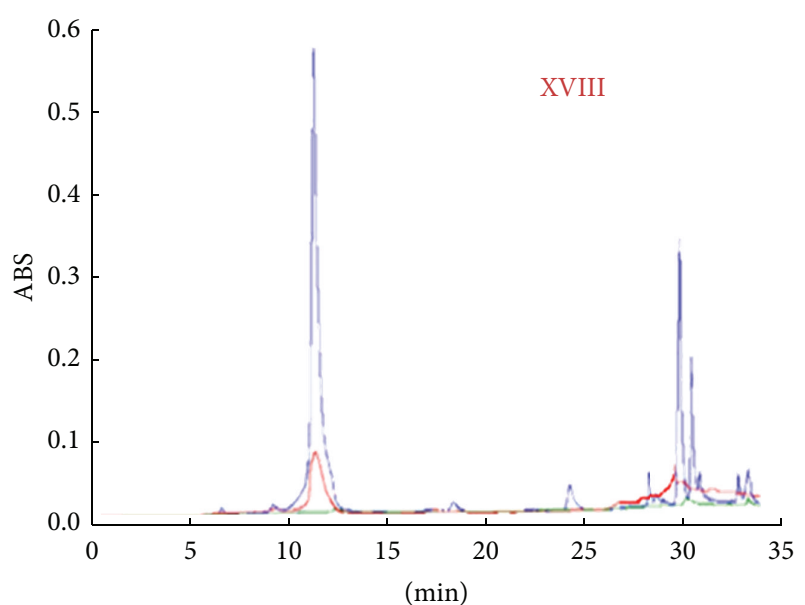

FIGURE 6: HPLC chromatograms of water extracts of paper fragments belonging XVIII century, soiled with linseed oil, aged and uncleaned (blue line), cleaned with Gellan gel (red line), and cleaned with Gellan/PLU gel (green line).

The comparison of FTIR spectra performed using Gellan gel with and without enzyme as cleaning agent on filter paper samples soiled with starch paste showed that the spectrum of paper coated with starch paste and treated with Enzymatic Gellan gel was similar to that of the uncoated paper samples, suggesting that such cleaning procedure is effective in removing starch paste. On the contrary, the spectra of paper, coated with starch paste and untreated or treated with Gellan gel, were comparable, indicating that it is not able to remove starch paste, at least after 60 minutes treatment (Figure 7) [31].

Moreover, the paper coated with starch paste showed an FTIR absorption spectrum different from that of the starting paper, due to the presence of the glue. Starch paste, in fact, showed a band at $998 \mathrm{~cm}^{-1}$, while cellulose has an absorption maximum at $1024 \mathrm{~cm}^{-1}$ [30]. The absorbance ratio between these two peaks Abs (1024)/Abs (998) was therefore diagnostic to verify the efficiency of the cleaning procedure. This ratio was $1.10 \pm 0.03$ for untreated paper and decreased to $0.69 \pm 0.05$ when paper was coated with starch paste. Treatment with the Enzymatic Gellan gel caused an increment of this ratio to $0.97 \pm 0.04$, very close to that of the uncoated paper; this was not the case of the starch paste coated paper cleaned with Gellan gel, as this ratio only to 0.72 .

\section{Sampling and Monitoring System Coupled with Electrochemical Biosensor}

No data were reported in the literature that allow checking if the cleaning procedure of paper artworks was working and, simultaneously, performing a screening of the degradation state of the sample. The monitoring of the cleaning process and the identification of the degradation products or pollutant removed are very important goal required by restorers, in order to verify the degradation conditions of the paper artworks and the cleaning efficiency of the adopted

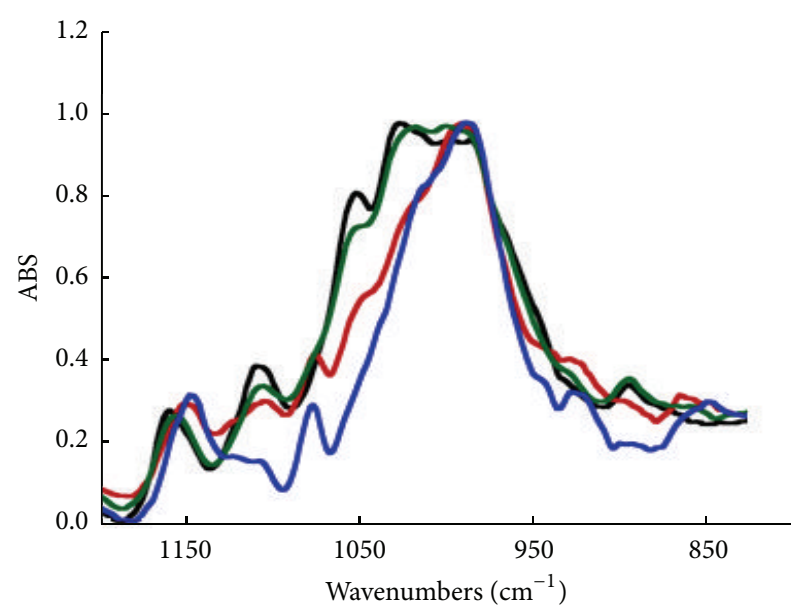

FIGURE 7: FTIR spectra of paper samples uncoated (black line), coated with starch paste (blue line), coated with starch paste after cleaning with Gellan gel (red line), and coated with starch paste and cleaned with Enzymatic Gellan gel (green line). Spectra are normalized to the maximum for clarity.

procedure. A system that also combines a gel, as cleaning agent, with a selective biosensor, specific for degradation products, is therefore a very useful procedure to clean the paper artwork without damage and to estimate the extent of degradation of the paper and the time needed to remove its products and pollution. During our research study, we developed a combining tool, composed of a flow sampling plate/hydrogel/electrochemical biosensor, in order to answer to this question. In particular, the flow sampling plate was designed "ad hoc" and was constituted of a plate in Perspex, on which there was a serpentine with 12 channels, in order to be affixed directly on the Gellan gel during cleaning up (Figure 8). The utility of this system is to wash away the pollution and degradation products (called "material") present on the paper by using the cleaning gel and, at the same time, to remove them from the gel itself during its application, through a continuous flow of buffer in the serpentine. This "material" crosses the gel by capillarity at the contact surface between the gel and the paper sample, reaching the opposite side, where the gel is in contact with the flow sampling plate. The collected solution was analyzed by a selected electrochemical biosensor. This system was also employed to quantify specific degradation products and to know the cleanup extent.

In this outlook, we report an application to monitor the status of conservation and the cleaning process of paper material, with the quantification of the degradation products of cellulose as an example of the potentiality of this tool. The selected degradation product was the glucose, produced on paper artwork after a simulated attack by hydrolytic cellulaseproducing fungi by use of a disposable glucose biosensor coupled with a flow sampling [32].

We chose this degradation product because it is one of the most common products of paper deterioration. Glucose is the final product of endogenous paper degradation, due to 


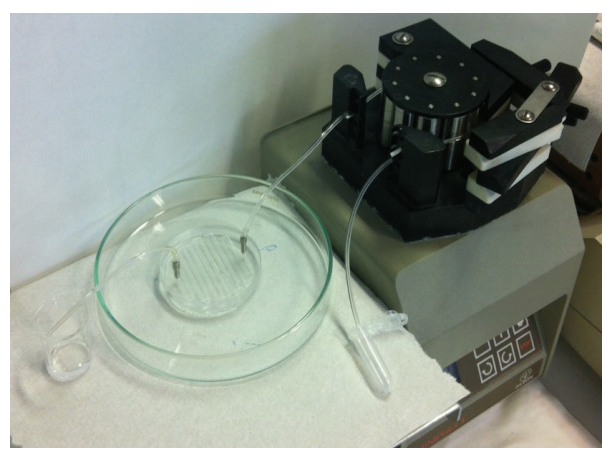

(a)

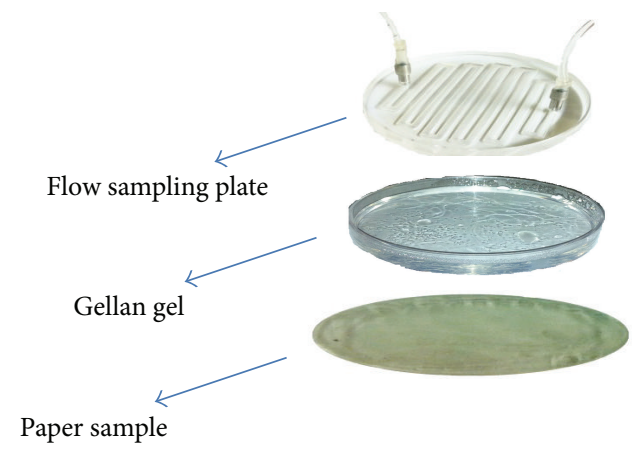

(b)

FIgURE 8: Flow sampling system applied to Gellan gel and paper sample.

the hydrolysis of cellulose (a structural component of paperbased materials) by a multicomponent enzymatic system called cellulase, produced by fungal species that attack and grow on the paper. In particular, Trichoderma reesei and Aspergillus niger fungi produce extracellular enzymes, called cellulases that metabolized cellulose sprouting mainly glucose $[33,34]$. The characteristics and the sensitivity of the glucose biosensor, based on the immobilization of the glucose oxidase (GOx) enzyme on screen printed electrode (SPE), are well known either in the literature or in the experience of our laboratory [35], based on the following reaction scheme:

$$
\text { Glucose }+\mathrm{O}_{2} \stackrel{\text { Glucose-oxidse }}{\longrightarrow} \text { Gluconic acid }+\mathrm{H}_{2} \mathrm{O}_{2}
$$

The produced $\mathrm{H}_{2} \mathrm{O}_{2}$ is detected amperometrically using a screen printed electrode modified with Prussian Blue ( $b \mathrm{~PB}-$ $\mathrm{SPE})$, at an applied potential of $-50 \mathrm{mV}$. The advantages of Prussian blue (PB) as catalyst for the reduction of the hydrogen peroxide [36] and the screen printing technology were combined to assemble a bulk-modified screen-printed electrode. By immobilizing the glucose oxidase (GOD) onto the working electrode area, a glucose biosensor was assembled and utilized for the detection of glucose produced during the enzymatic degradation of cellulose-based materials under the action of Aspergillus niger and Trichoderma reesei cellulases.

The study of the proposed system was evaluated using a not-aged commercial filter paper as a model sample to test the proposed tool, before analyzing real paper artworks. The monitoring of the cleaning procedure was carried out using paper samples, soaked with several glucose standard solutions and dried at $37^{\circ} \mathrm{C}$ for $2 \mathrm{~h}$. The fortified paper samples were prepared in order to estimate the sensitivity and the repeatability of the analysis and the application and the sampling time of the gel on the paper sample. The "application time" corresponds to the time necessary to remove the maximum amount of glucose from the paper by the gel, while the "sampling time" indicates the time interval between two different samples of material removed from the flow sampling system from the surface of the gel. The flow sampling plate was applied directly onto the Gellan gel during the cleaning procedure. All analytical parameters of flow system/biosensor were studied and optimized, like the flow rate $(0.1 \mathrm{~mL} / \mathrm{min})$, the sampling time $(10 \mathrm{~min})$, the working buffer $(0.05 \mathrm{mM}$ phosphate buffer $+\mathrm{KCl} 0.1 \mathrm{M}$, $\mathrm{pH}$ 7.4), and the applied potential for electrochemical measurement ( $-50 \mathrm{mV}$ versus pseudoreference Ag). All collected solutions, in output from the plate, were analyzed using an electrochemical glucose biosensor $(60 \mu \mathrm{L}$ of solution was dropped on the electrode). The specific biosensor for glucose determination, based on screen printed electrodes (SPEs) produced in our laboratory, was prepared following the procedure reported elsewhere, modifying the electrode with Prussian Blue (PB) and immobilizing 0.37 U of GOx [35]. Amperometric measurements were carried out using a portable PalmSens potentiostat (Palm Instruments BV, The Netherlands) connected to a laptop computer.

Application time of Gellan gel was evaluated using a fortified paper with $10^{-3} \mathrm{M}$ of glucose and treated as reported before. The current values were registered every $10 \mathrm{~min}$ and reported in function of the sampling time. The concentrations of glucose, removed by the gel, were extrapolated for each collected solution, using the calibration curve for glucose biosensor (LOD $2 \times 10^{-5} \mathrm{M}$; RSD\%: $2 \%, n=6$ for each concentration; linearity range: $10^{-5} \mathrm{M}-10^{-3} \mathrm{M}$, Figure 9), obtained with standard solution absorbed by filter paper, and removed by gel after $1 \mathrm{~h}(60 \mu \mathrm{L}$ of solution dropped on the electrode). The results obtained during the sampling study show that the maximum amount of glucose was removed by the cleaning process after $60 \mathrm{~min}$ and that it could be solved after $150 \mathrm{~min}$. Moreover, the dilution factor of the glucose absorbed by the paper and removed from the gel was also calculated ( $(\mathrm{g}$ glucose present in collected solution/g glucose content in the paper) $* 100)$, showing a trend increasing with time (1: $25 \mathrm{v} / \mathrm{v}$ after $60 \mathrm{~min}$ and $1: 60 \mathrm{v} / \mathrm{v}$ after $150 \mathrm{~min}$; RSD\% intrasample $=6 \%, n=3$ ). This phenomenon was due to both the water present in the gel and the buffer flow.

\section{Application of Monitoring and Cleaning Tool to Real Paper Samples}

The proposed system for the monitoring of the cleaning procedure of the paper by Gellan gel was evaluated by simulation of the attack of the cellulase enzyme of paper samples produced industrially, such as newsprint paper, parchment paper, and filter paper. In addition, it was also 


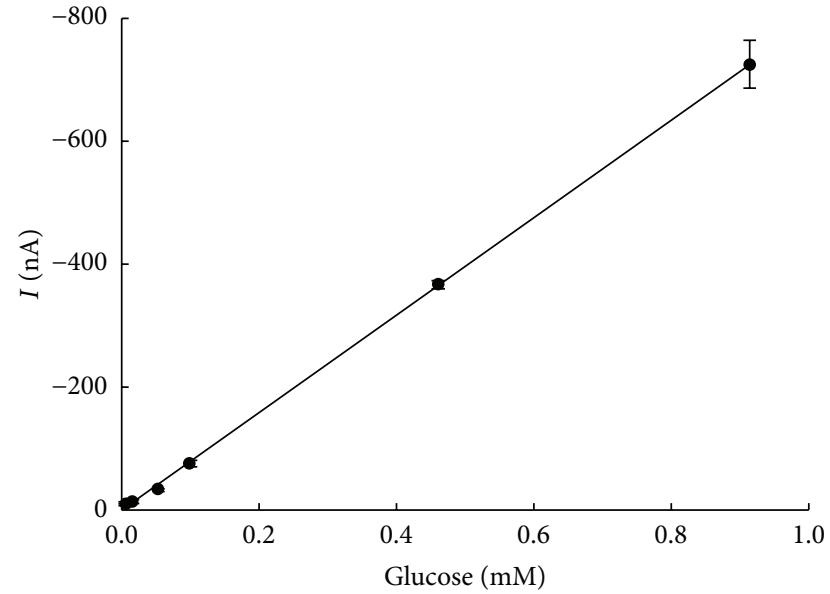

FIGURE 9: Calibration curve for glucose absorbed on filter paper and removed by gel $\left(y=-792645 x+5 ; r^{2}=0.996\right)$. Electrochemical technique: amperometry; evaluated current after $180 \mathrm{~s}$; applied potential $-50 \mathrm{mV}$ versus pseudoreference $\mathrm{Ag}$; working buffer: $50 \mathrm{mM}$ phosphate buffer $+0.1 \mathrm{M} \mathrm{KCl}, \mathrm{pH}$ 7.4.

applied to the book pages printed in 1966 in not perfect storage conditions (yellowed paper).

4.1. Paper Characterization. The composition of paper samples (old book paper (1966), newspaper, parchment paper, and filter paper) was estimated by exposure of the paper fibers to dye Graff "C" [9]. The color of the paper obtained after treatment with the Graff " $\mathrm{C}$ " depends on the amount of cellulose present compared to the lignin content; the different percentages of these two molecules, cellulose and lignin, depend, in turn, on the raw materials used to produce the paper such as cotton and softwood (Table 2, Figure 10).

4.2. Enzymatic Degradation of Paper and Electrochemical Measurement. The characterized paper samples (sample of $36 \mathrm{~cm}^{2}$ ) underwent enzymatic degradation by commercial cellulase from Aspergillus niger $(1.0 \mathrm{U} / \mathrm{mg})$ and from Trichoderma reesei $(6.3 \mathrm{U} / \mathrm{mg})$. An enzyme concentration of $5 \mathrm{mg} / \mathrm{mL}$ for each cellulase or $1: 1 \mathrm{w} / \mathrm{w}$ ratio of these two cellulases (final concentration $5 \mathrm{mg} / \mathrm{mL}$ ) was brush-strokes on the papers and enzymatic reaction was carried out for $2 \mathrm{~h}$ at $25^{\circ} \mathrm{C}$. The chosen $\mathrm{pH}(\mathrm{pH}$ 6.0) for the enzymatic degradation process was a compromise between the optimal $\mathrm{pH}$ range of cellulase enzymatic activity ( $\mathrm{pH} 4.5-6.5)$ and the normal $\mathrm{pH}$ values of the paper-based material in normal storage conditions (pH 6.5-8.0) [37]. The enzymatic reaction was stopped after $2 \mathrm{~h}$ and the proposed system (Gellan gel/flow sampling plate) was applied on the paper samples. The solution, in output of the system, was collected for $1 \mathrm{~h}$. The amount of glucose produced by enzymatic reaction was monitored using the glucose biosensor, as illustrated before. Paper samples exhibit different susceptibilities towards cellulase action that can be linked to structural parameters such as crystalline and amorphous regions, since more crystalline regions in the substrate would offer stronger resistance towards enzymatic
TABLE 2: Color of the paper samples obtained after treatment with the Graff "C".

\begin{tabular}{lcc}
\hline Sample & Color after Graff "C" & Composition \\
\hline Pure cellulose & Brown-red & Cotton \\
Filter paper & Blue & Softwood pulp \\
Newspaper & Brown-purple & Softwood pulp \\
Book(1966) & Red & $?$ \\
Parchment & Brown-red & Cotton \\
\hline
\end{tabular}

degradation [38]. The results (Table 3) showed that the amount of glucose $(\mathrm{mM})$ produced after enzymatic attack was as a function of the composition of the paper and of the percentage of cellulose present in it. For example, filter paper is composed of pure cellulose and its structure is rich in crystalline regions, not easy to be hydrolyzed by enzymes; therefore, the amount of measured glucose from filter paper is the lowest. On the contrary, newspaper is poor in cellulose, but rich in lignin and endocellulase that create amorphous regions inside of the paper, ideal substrate for fungi attack. It shows the highest amount of measured glucose.

Using a mix of the two cellulases $(5 \mathrm{mg} / \mathrm{mL}, 1: 1 \mathrm{w} / \mathrm{w})$ we observed a clear effect of the synergistic action of the combined complex of enzymes. The parchment paper, under the combined action of the two cellulases, produced the highest amount of glucose.

\section{Conclusion}

Further efforts have to be done in order to know how to perform the best possible restoration of paper artworks. In this research work, the monitoring of simulated cleaning processes showed that the association of Gellan gel and flow sampling plate was important for following the cleanup of paper artworks [32]. During this study, the use of Gellan gel, as paper cleaning material, is useful in removing mainly hydrophilic molecules from paper artworks, without damage and also without activating anomalous long-term degradation [9]. The novelty offered by this cleaning gel, compared to the traditional one, resides in the possibility to modulate and adjust the amount of water absorbed on paper samples, according to the wet ability of each paper sample.

This hydrogel can be also modified adding surfactants or enzyme in order to remove hydrophobic molecules or glue with high yield $[25,26,31]$. Highly potential electrochemical biosensors, which have been widely employed in other scientific areas, too, may be used to know the cleanup extent of the gels used, which, in turn, are shown to be highly efficient in removing pollutants and degradation products. In fact, by choosing the appropriate enzymes to be immobilized, selective biosensors for substances to be removed from the gel have been obtained. In this way, it is possible to know when the cleanup process will be completed, avoiding lengthy and sometimes unnecessary cleaning material applications. For example, in the case of the degradation compounds and pollution of paper, the combination of glucose biosensor and gel would allow the restorers to determine when the process 


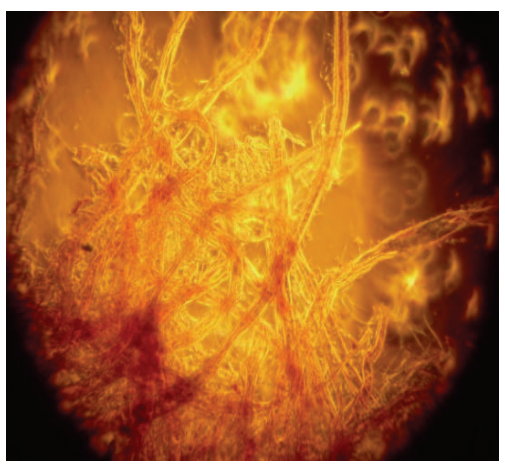

(a)

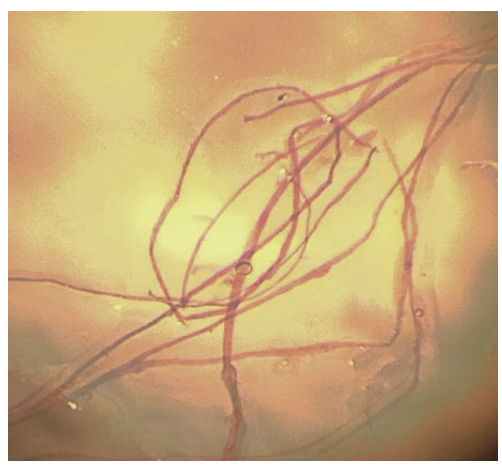

(b)

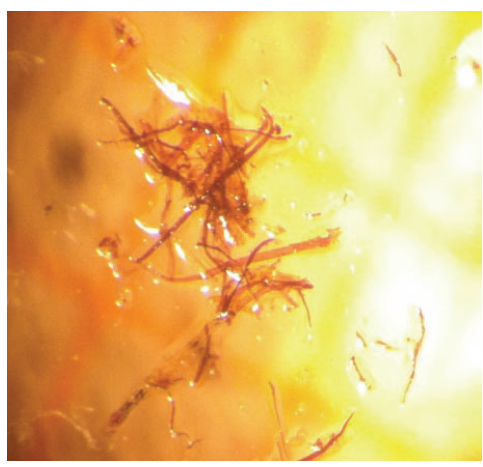

(c)

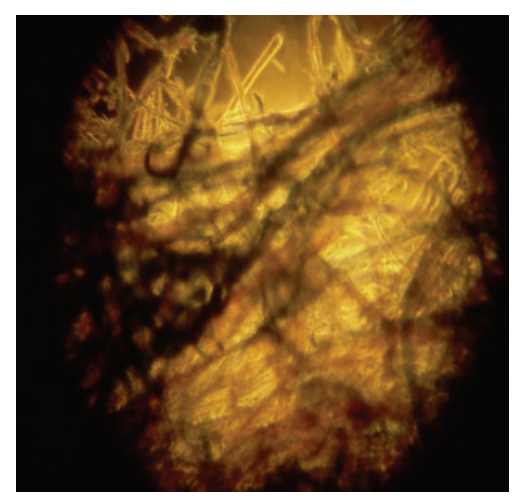

(d)

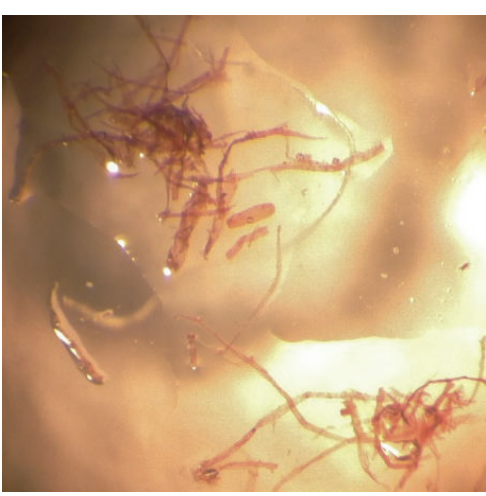

(e)

FIGURE 10: Optical microscope images of paper samples after treatment with Graf “C”. (a) Pure cellulose, (b) parchment paper, (c) newspaper, (d) filter paper, and (e) book page.

TABLE 3: Concentration of glucose produced by simulated enzymatic attack.

\begin{tabular}{lcc}
\hline & Filter paper & \\
Aspergillus niger & & $(3.0 \pm 0.2) \times 10^{-3} \mathrm{M}$ \\
Trichoderma reesei & & $(2.0 \pm 0.2) \times 10^{-3} \mathrm{M}$ \\
Mix & & $(5.2 \pm 0.2) \times 10^{-3} \mathrm{M}$ \\
\hline & Newspaper paper & \\
Aspergillus niger & & $(8.5 \pm 0.7) \times 10^{-3} \mathrm{M}$ \\
Trichoderma reesei & & $(2.8 \pm 0.2) \times 10^{-3} \mathrm{M}$ \\
Mix & & $(10.1 \pm 0.9) \times 10^{-3} \mathrm{M}$ \\
\hline & Parchment paper & \\
Aspergillus niger & & $(3.8 \pm 0.5) \times 10^{-3} \mathrm{M}$ \\
Trichoderma reesei & & $(5.7 \pm 0.7) \times 10^{-3} \mathrm{M}$ \\
Mix & & $(12 \pm 2) \times 10^{-3} \mathrm{M}$ \\
\hline & & \\
Aspergillus niger & Book (1966) & $(3.0 \pm 0.3) \times 10^{-3} \mathrm{M}$ \\
Trichoderma & & $(2.3 \pm 0.8) \times 10^{-3} \mathrm{M}$ \\
Mix & & $(5 \pm 1) \times 10^{-3} \mathrm{M}$ \\
\hline
\end{tabular}

of removing this degradation product of cellulose is finished and to evaluate the cleaning efficiency [8].

In conclusion, this brief presentation summarizes an interdisciplinary research work that is being carried out together with restorers of ICPAL and the Laboratories of
Analytical Chemistry and Physical Chemistry of University of Rome Tor Vergata. The results, obtained until now, are satisfactory and show the effectiveness and the potentiality of the proposed system in terms of degree of cleanup, of compatibility either with the material to be treated or with the operator, and of efficiency of monitoring the state of conservation of the material to be restored.

\section{Conflict of Interests}

The authors declare that there is no conflict of interests regarding the publication of this paper.

\section{Authors' Contribution}

Laura Micheli and Claudia Mazzuca have equally contributed to this paper.

\section{Acknowledgments}

This work was supported by the "progetto SIDE" of the Regione Lazio. The authors thank Dr. Francesco Basoli, Prof. Danila Moscone, and Dr. Raffaella Lettieri for technical support and useful discussions. They are grateful to Simonetta Iannuccelli and Silvia Sotgiu, restorers of ICPAL of Rome, for their practical support and useful discussions. 


\section{References}

[1] M. Copedè, La Carta ed il Suo Degrado, Firenze, Italy, Nardini, 1995.

[2] M. T. Doménech-Carb, "Novel analytical methods for characterization of binding media and protective coatings in artworks," Analytica Chimica Acta, vol. 621, pp. 109-139, 2008.

[3] J. L. Ramírez, M. A. Santana, I. Galindo-Castro, and A. Gonzalez, "The role of biotechnology in art preservation," Trends in Biotechnology, vol. 23, no. 12, pp. 584-588, 2005.

[4] M. I. Prodromidis and M. I. Karayannis, "Enzyme based amperometric biosensors for food," Electroanal, vol. 14, no. 4, pp. 241-261, 2002.

[5] K. R. Rogers, "Enzyme based amperometric biosensors for food analysis," Biosensors and Bioelectronics, vol. 10, no. 6-7, pp. 533541, 1995.

[6] Quaderno Cesmar7n. 11 (2012), S. Iannuccelli e S. Sotgiu eds, il Prato, Padua.

[7] W. Gibson and G. R. Sanderson, "Gellan gum," in Thinckening and Gelling Agents for Food, A. Imeson, Ed., Aspen Publishers, New York, NY, USA, 1999.

[8] L. Micheli, C. Mazzuca, A. Palleschi, and G. Palleschi, "Combining a hydrogel and an electrochemical biosensor to determine the extent of degradation of paper artworks," Analytical and Bioanalytical Chemistry, vol. 403, no. 6, pp. 1485-1489, 2012.

[9] C. Mazzuca, L. Micheli, M. Carbone et al., "Gellan hydrogel as a powerful tool in paper cleaning process: a detailed study," Journal of Colloid and Interface Science, vol. 416, pp. 205-211, 2014.

[10] G. Sworn, "Gellan gum," in Handbook of Hydrocolloids, G. O. Philips and P. A. Williams, Eds., CRC Press/Woodhead, Cambridge, UK, 2000.

[11] I. B. Bajaj, S. A. Survase, P. S. Saudagar, and R. S. Singhal, "Gellan gum: fermentative production, downstream processing and applications," Food Technology and Biotechnology, vol. 45, no. 4, pp. 341-354, 2007.

[12] A. Ohtsuka and T. Watanabe, "The network structure of gellan gum hydrogels based on the structural parameters by the analysis of the restricted diffusion of water," Carbohydrate Polymers, vol. 30, no. 2-3, pp. 135-140, 1996.

[13] P. Matricardi, C. Cencetti, R. Ria, F. Alhaique, and T. Coviello, "Preparation and characterization of novel Gellan gum hydrogels suitable for modified drug release," Molecules, vol. 14, no. 9, pp. 3376-3391, 2009.

[14] E. Miyoshi, T. Takaya, and K. Nishinari, "Effects of salts on the gel-sol transition of gellan gum by differential scanning calorimetry and thermal scanning rheology," Thermochimica Acta, vol. 267, pp. 269-287, 1995.

[15] S. Ikeda, Y. Nitta, T. Temsiripong, R. Pongsawatmanit, and K. Nishinari, "Atomic force microscopy studies on cation-induced network formation of gellan," Food Hydrocolloids, vol. 18, no. 5, pp. 727-735, 2004.

[16] E. R. Morris, K. Nishinari, and M. Rinaudo, "Gelation of gellan-a review," Food Hydrocolloids, vol. 28, no. 2, pp. 373-411, 2012.

[17] A. Casoli, E. Cervelli, P. Cremonesi et al., "La verifica del metodo," in Collana Quaderno Cesmar7, S. Iannuccelli and S. Sotgiu, Eds., vol. 11, pp. 37-57, Padova, Italy, 2012.

[18] J. Vodopivec and M. Cernic, "Non destructive characterization of paper as a support of a gouache collection," in Proceedings of the 9th International conference on NDT of Art, Jerusalem, Israel, May 2008.
[19] P. Calvini and A. Gorassini, "FTIR-deconvolution spectra of paper documents," Restaurator, vol. 23, no. 1, pp. 48-66, 2002.

[20] J. Łojewska, P. Miśkowiec, T. Łojewski, and L. M. Proniewicz, "Cellulose oxidative and hydrolytic degradation: in situ FTIR approach," Polymer Degradation and Stability, vol. 88, no. 3, pp. 512-520, 2005.

[21] J. Lojewska, A. Lubanska, T. Lojewski, P. Miscowiec, and L. M. Proniewicz, "Kinetic approch to degradation of paper," $e$ Preservation Science, vol. 2, p. 1, 2005.

[22] J. Li, X. Ni, and K. W. Leong, "Injectable drug-delivery systems based on supramolecular hydrogels formed by poly(ethylene oxide)s and $\alpha$-cyclodextrin," Journal of Biomedical Materials Research A, vol. 65, no. 2, pp. 196-202, 2003.

[23] J. Li, X. Li, X. Ni, X. Wang, H. Li, and K. W. Leong, "Selfassembled supramolecular hydrogels formed by biodegradable PEO-PHB-PEO triblock copolymers and $\alpha$-cyclodextrin for controlled drug delivery," Biomaterials, vol. 27, no. 22, pp. 4132 4140, 2006.

[24] J. Li and X. J. Loh, "Cyclodextrin-based supramolecular architectures: syntheses, structures, and applications for drug and gene delivery," Advanced Drug Delivery Reviews, vol. 60, no. 9, pp. 1000-1017, 2008.

[25] C. Mazzuca, L. Micheli, F. Marini et al., "Rheoreversible hydrogels in paper restoration processes: a versatile tool," Chemistry Central Journal, vol. 8, no. 1, pp. 1-11, 2014.

[26] C. Mazzuca, G. Bocchinfuso, I. Cacciotti, L. Micheli, G. Palleschi, and A. Palleschi, "Versatile hydrogels: an efficient way to clean paper artworks," RSC Advances, vol. 3, no. 45, pp. 22896-22899, 2013.

[27] F. Fiorani and G. Pace, "I disegni di Étienne Du Pérac per i "Vestigi dell'antichità di Roma". Le prime carte traslucide," Mitteilungen des Kunsthistorisches Institut in Florenz, vol. 2, no. 2-3, pp. 240-251, 2008.

[28] A. Gambaro, R. Ganzerla, M. Fantin, E. Cappelletto, R. Piazza, and W. R. L. Cairns, "Study of 19th century inks from archives in the Palazzo Ducale (Venice, Italy) using various analytical techniques," Microchemical Journal, vol. 91, no. 2, pp. 202-208, 2009.

[29] M. Lazzari and O. Chiantore, "Drying and oxidative degradation of linseed oil," Polymer Degradation and Stability, vol. 65, no. 2, pp. 303-313, 1999.

[30] V. Librando, Z. Minniti, and S. Lorusso, "Ancient and modern paper characterization by FTIR and Micro-Raman spectroscopy," Conservation Science in Cultural Heritage, vol. 11, no. 1, pp. 249-268, 2011.

[31] C. Mazzuca, L. Micheli, E. Cervelli et al., "Development of a new efficient strategy to remove starch paste from paper samples," under review to ACS Applied Materials \& Interfaces.

[32] L. Micheli, C. Mazzuca, D. Moscone, A. Palleschi, and G. Palleschi, "Electrochemical technique for Cultural heritage. An example of application of monitoring cleaning process of paper art work," in Facciamo Germogliare le Nostre Idee-Quaderno della III Scuola di Chimica Ambientale e dei beni Culturali, E. Papa, M. Grazia Perrone, A. Piazzalunga, and B. Varese, Eds., pp. 77-81, Società Chimica Italiana, 2014.

[33] M. Strlic, J. Kolar, and S. Scholten, "Paper and durability," in Ageing and stabilization of paper, M. Strlic and J. Kolar, Eds., Ljubljana National and University Library, Ljubljana, Slovenia, 2005.

[34] T. M. Wood, "Fungal cellulases," Biochemical Society Transactions, vol. 20, no. 1, pp. 46-53, 1992. 
[35] M. Mahosenaho, F. Caprio, L. Micheli, A. M. Sesay, G. Palleschi, and V. Virtanen, "A disposable biosensor for the determination of alpha-amylase in human saliva," Microchimica Acta, vol. 170, no. 3, pp. 243-249, 2010.

[36] A. A. Karyakin and E. E. Karyakina, "Electroanalytical applications of Prussian Blue and its analogs," Russian Chemical Bulletin, vol. 50, no. 10, pp. 1811-1817, 2001.

[37] M. Itävaara, M. Siika-aho, and L. Viikari, "Enzymatic degradation of cellulose-based materials," Journal of Environmental Polymer Degradation, vol. 7, no. 2, pp. 67-73, 1999.

[38] S. Lorusso, F. Prestileo, L. Gregari, and M. E. Pifferi, "Tecnica, tecnologia, scienza nel settore dei beni culturali," Scienza e Tecnica, vol. 340, pp. 1-17, 1999. 

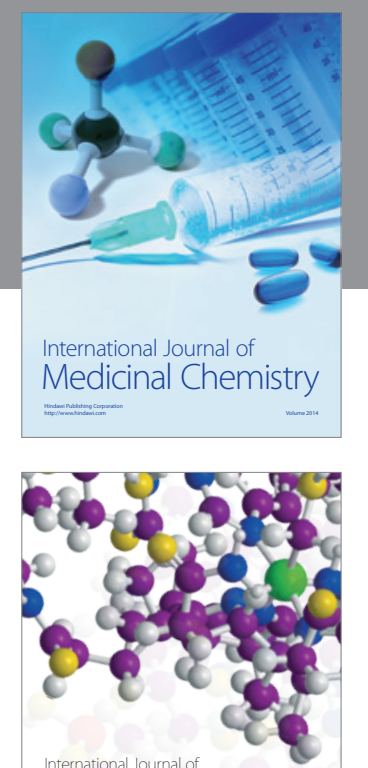

\section{Carbohydrate} Chemistry

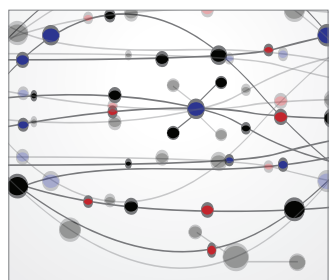

The Scientific World Journal
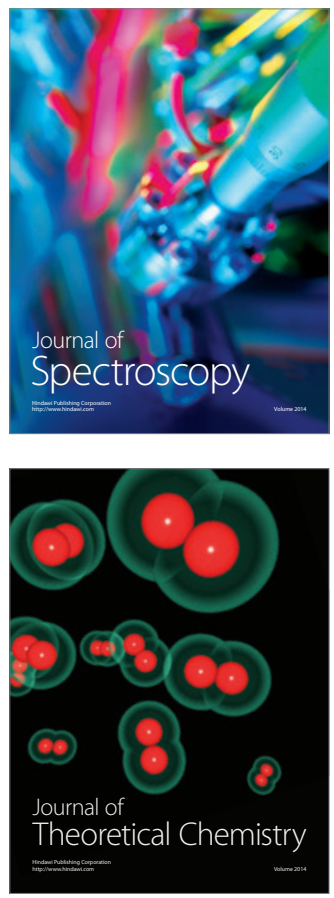
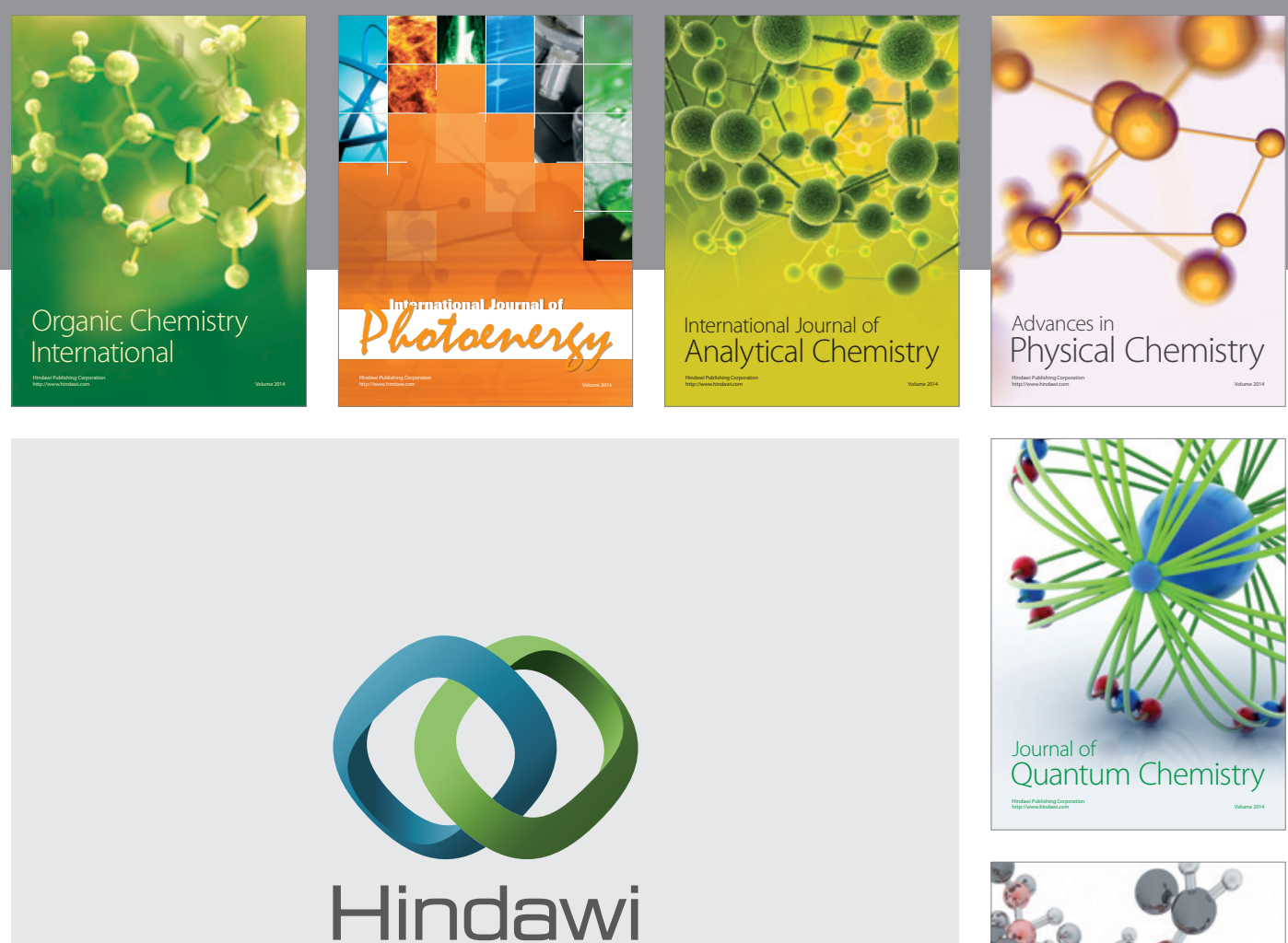

Submit your manuscripts at

http://www.hindawi.com

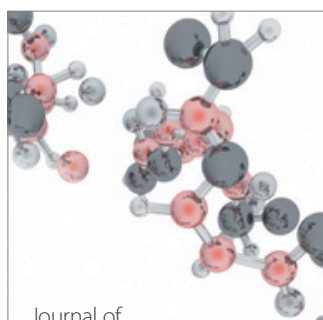

Analytical Methods

in Chemistry

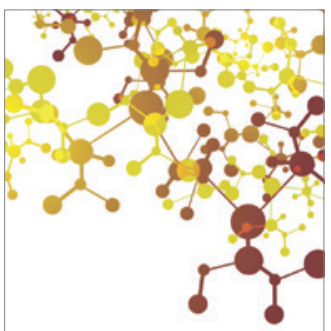

Journal of

Applied Chemistry

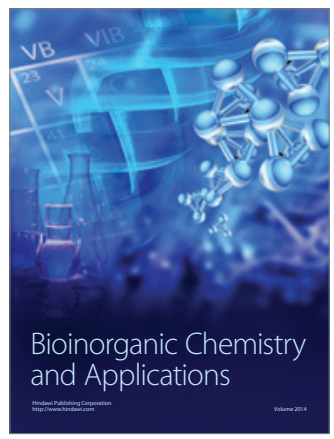

Inorganic Chemistry
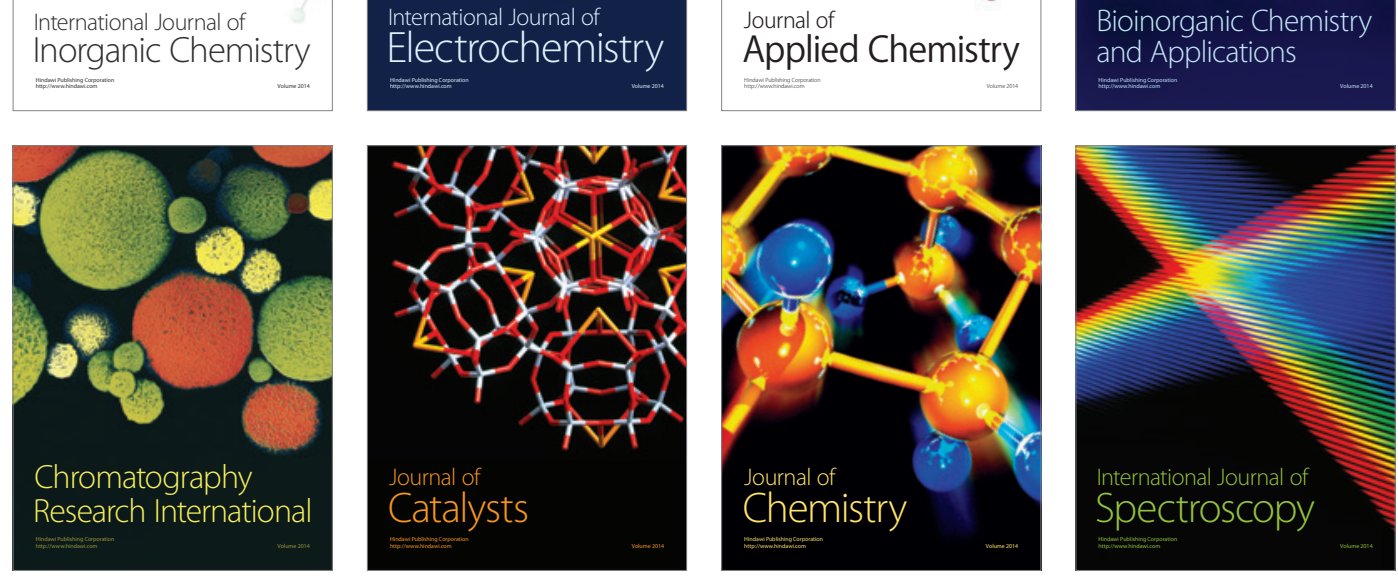